DR JIAGANG WU (Orcid ID : 0000-0002-9960-9275)

Article type : Article

\title{
Structural Evolution of the R-T Phase Boundary in KNN-Based Ceramics
}

Xiang $\mathrm{Lv}^{\mathrm{a}, \mathrm{b}}$, Jiagang $\mathrm{Wu}^{\mathrm{a}^{*}}$, Dingquan $\mathrm{Xiao}^{\mathrm{a}}$, Jianguo Zhu ${ }^{\mathrm{a}}$ and Xixiang Zhang ${ }^{\mathrm{b}^{*}}$

${ }^{a}$ Department of Materials Science, Sichuan University, Chengdu, 610064, P. R. China

${ }^{b}$ King Abdullah University of Science and Technology (KAUST), Physical Science and

Engineering Division (PSE), Thuwal 23955-6900, Saudi Arabia

Abstract: Although a rhombohedral-tetragonal (R-T) phase boundary is known to substantially enhance the piezoelectric properties of potassium-sodium niobate ceramics, the structural evolution of the R-T phase boundary itself is still unclear. In this work, the structural evolution of R-T phase boundary from $-150{ }^{\circ} \mathrm{C}$ to $200{ }^{\circ} \mathrm{C}$ is investigated in $(0.99-x) \mathrm{K}_{0.5} \mathrm{Na}_{0.5} \mathrm{Nb}_{1-y} \mathrm{Sb}_{y} \mathrm{O}_{3}-0.01 \mathrm{CaSnO}_{3}-x \mathrm{Bi}_{0.5} \mathrm{~K}_{0.5} \mathrm{HfO}_{3}$ (where $x=0 \sim 0.05$ with $y=0.035$, and

a) Email: msewujg@scu.edu.cn and wujiagang0208@163.com

b) Email: xixiang.zhang@kaust.edu.sa

This article has been accepted for publication and undergone full peer review but has not been through the copyediting, typesetting, pagination and proofreading process, which may lead to differences between this version and the Version of Record. Please cite this article as doi: $10.1111 /$ jace. 15266

This article is protected by copyright. All rights reserved. 
$y=0 \sim 0.07$ with $x=0.03$ ) ceramics. Through temperature-dependent powder X-ray diffraction (XRD) patterns and Raman spectra, the structural evolution was determined to be Rhombohedral $\left(R,<-125^{\circ} \mathrm{C}\right) \rightarrow$ Rhombohedral+Orthorhombic $\left(R+O,-125{ }^{\circ} \mathrm{C}\right.$ to $\left.0{ }^{\circ} \mathrm{C}\right) \rightarrow$ Rhombohedral + Tetragonal $\left(R+T, 0{ }^{\circ} \mathrm{C}\right.$ to $\left.150{ }^{\circ} \mathrm{C}\right) \rightarrow$ dominating Tetragonal $\left(T, 200{ }^{\circ} \mathrm{C}\right.$ to Curie temperature $\left.\left(T_{\mathrm{C}}\right)\right) \rightarrow$ Cubic $\left(C,>T_{\mathrm{C}}\right)$. In addition, the enhanced electrical properties (e.g., a direct piezoelectric coefficient $\left(d_{33}\right)$ of $\sim 450 \pm 5 \mathrm{pC} / \mathrm{N}$, a conversion piezoelectric coefficient $\left(d_{33}{ }^{*}\right)$ of $\sim 580 \pm 5 \mathrm{pm} / \mathrm{V}$, an electromechanical coupling factor $\left(k_{\mathrm{p}}\right)$ of $\sim 0.50 \pm 0.02$, and $T_{\mathrm{C}} \sim 250$ $\left.{ }^{\circ} \mathrm{C}\right)$, fatigue-free behavior, and good thermal stability were exhibited by the ceramics possessing the R-T phase boundary. This work improves understanding of the physical mechanism behind the R-T phase boundary in KNN-based ceramics and is an important step towards their adoption in practical applications.

Keywords: KNN; Electrical properties; R-T phase boundary; Structural evolution

\section{Introduction}

Piezoelectric materials, which can invert mechanical energy into electrical energy and vice versa, are extensively used in many kinds of electronic devices, such as sensors and actuators [1]. Currently, the market is dominated by materials based on lead zirconate titanate (PZT) due to their exceptional piezoelectric properties [2]. Unfortunately, the high concentration of toxic lead - over $60 w t \%$ - causes serious harm to human health and 
contaminates the environment. Therefore, there is an urgent need to develop high-performance lead-free piezoceramics to replace the lead-based materials [3].

Three kinds of lead-free piezoelectric materials with a perovskite structure have been widely investigated: barium titanate $\left[\mathrm{BaTiO}_{3}, \mathrm{BT}\right]$, sodium-bismuth titanate $\left[(\mathrm{Bi}, \mathrm{Na}) \mathrm{TiO}_{3}, \mathrm{BNT}\right]$, and potassium-sodium niobate $\left[(\mathrm{K}, \mathrm{Na}) \mathrm{NbO}_{3}, \mathrm{KNN}\right]$ [3]. $\mathrm{KNN}$-based ceramics have exhibited the potential to replace lead-based materials since Saito et al. achieved a large $d_{33}$ of $416 \mathrm{pC} / \mathrm{N}$ in highly textured LF4T ceramics [4]. Recently, the construction of a rhombohedral-tetragonal (R-T) phase boundary was reported to effectively improve the piezoelectric properties of KNN-based ceramics, resulting in giant $d_{33}$ values of $490 \sim 570$ $\mathrm{pC} / \mathrm{N}[5,6]$. Although the existence of an R-T phase boundary substantially improves the piezoelectric properties, knowledge about the structural evolution of the R-T phase boundary itself from a low temperature to a high temperature is still lacking [7]. Since the piezoelectric properties are known to be closely related to the phase structure of a piezoceramic [8], a systematic study of the R-T phase boundary from low to high temperatures is highly anticipated. In addition, the effects of the R-T phase boundary on the electrical properties, fatigue behavior, and thermal stability of ceramics still need to be further evaluated in the context of practical applications [9].

In this work, we investigate the structural evolution of the R-T phase boundary and unveil its effects on the performance of KNN-based ceramics by means of temperature-dependent XRD patterns and Raman spectra. To construct the R-T phase boundary, we doped pure KNN 
ceramics with additives (e.g., $\mathrm{Sb}^{5+}, \mathrm{Bi}_{0.5} \mathrm{Na}_{0.5} \mathrm{HfO}_{3}, \mathrm{CaZrO}_{3}$ ) in order to shift the rhombohedral-orthorhombic $\left(T_{\mathrm{R}-\mathrm{O}}\right)$ and orthorhombic-tetragonal $\left(T_{\mathrm{O}-\mathrm{T}}\right)$ phase transition temperatures to room temperature [10-12]. In addition, due to the similar ion radii of $\mathrm{Zr}^{4+}$ $\left(0.71 \AA\right.$ ) and $\mathrm{Sn}^{4+}(0.69 \AA)$, it is reasonable to replace $\mathrm{CaZrO}_{3}$ with $\mathrm{CaSnO}_{3}$, which has not been investigated previously. We used the $(0.99-x) \mathrm{K}_{0.5} \mathrm{Na}_{0.5} \mathrm{Nb}_{1-y} \mathrm{Sb}_{y} \mathrm{O}_{3}-0.01 \mathrm{CaSnO}_{3}-x \mathrm{Bi}_{0.5} \mathrm{~K}_{0.5} \mathrm{HfO}_{3}$ (KNNS-CS-BKH) (where $x=0 \sim 0.05$ with $y=0.035$, and $y=0 \sim 0.07$ with $x=0.03$ ) ceramics to explore these issues.

\section{Experimental procedures}

$(0.99-x) \mathrm{K}_{0.5} \mathrm{Na}_{0.5} \mathrm{Nb}_{1-y} \mathrm{Sb}_{y} \mathrm{O}_{3}-0.01 \mathrm{CaSnO}_{3}-x \mathrm{Bi}_{0.5} \mathrm{~K}_{0.5} \mathrm{HfO}_{3}$ (where $x=0 \sim 0.05$ with $y=0.035$, and $y=0 \sim 0.07$ with $x=0.03$ ) ceramics were developed by using the conventional solid-state reaction method. The raw materials were $\mathrm{K}_{2} \mathrm{CO}_{3}(99 \%), \mathrm{Na}_{2} \mathrm{CO}_{3}(99.8 \%), \mathrm{Nb}_{2} \mathrm{O}_{5}(99.5 \%)$, $\mathrm{Sb}_{2} \mathrm{O}_{3}(99.99 \%), \mathrm{CaCO}_{3}$ (99.9\%), $\mathrm{SnO}_{2}$ (99.0\%), $\mathrm{Bi}_{2} \mathrm{O}_{3}$ (99.999\%), and $\mathrm{HfO}_{2}$ (99\%). All of the raw materials were precisely weighted by using a precision electronic balance. Then, the weighted powders were ball-milled for $24 \mathrm{~h}$ with alcohol as the dispersion medium. After ball-milling, the raw materials were dried and calcined at $850{ }^{\circ} \mathrm{C}$ for $6 \mathrm{~h}$ in air. The calcined powders were pressed into green pellets with $\sim 10 \mathrm{~mm}$ diameter and $\sim 1 \mathrm{~mm}$ thickness under a pressure of $10 \mathrm{MPa} ; 8 w t \%$ polyvinyl alcohol (PVA) was used as a binder. After burning off the PVA, the pellets were sintered at $1065^{\sim 1100}{ }^{\circ} \mathrm{C}$ for $3 \mathrm{~h}$ in air, and a direct current (DC) field of $4.0 \mathrm{kV} / \mathrm{mm}$ was used to pole the samples at $25{ }^{\circ} \mathrm{C}$ in a silicone oil bath.

This article is protected by copyright. All rights reserved. 
The phase structures of the ceramics were characterized by X-ray diffraction (XRD) (Bruker D8 Advanced XRD, Bruker axs Inc., Madison, WI, CuK $\alpha$ ) with a temperature controller. The temperature $\left(-150\right.$ to $200{ }^{\circ} \mathrm{C}$ and 20 to $400{ }^{\circ} \mathrm{C}$ ) dependencies of the relative dielectric constant $\left(\varepsilon_{\mathrm{r}}\right)$ of each sample were measured using a programmable furnace with an LCR analyzer (HP 4980, Agilent, USA). The Raman spectra were recorded on a Horiba Aramis Raman spectrometer (Horiba Scientific) with excitation sources of $473 \mathrm{~nm}$, and the measurement temperature was maintained by a temperature controller. For the Rietveld refinement, the as-sintered samples were ground into powders, then annealed at $600{ }^{\circ} \mathrm{C}$ for $30 \mathrm{~min}$ to eliminate internal stress. The Maud software package was used to conduct the refinement.

Field emission-scanning electron microscopy (FE-SEM) (JSM-7500, Japan) was used to measure the surface morphologies and elemental mappings of the ceramics. For the PFM measurements, the as-sintered samples were mechanically polished to $\sim 60 \mu \mathrm{m}$ thickness. The PFM experiments were carried out using commercial atomic force microscopy (MFP-3D) (Asylum Research, Goleta, CA). The vertical PFM images were characterized using a conductive Pt-Ir coated cantilever (Bruker) under an alternating voltage (AC) with an amplitude of $3 \mathrm{~V}(\mathrm{Uac}=3 \mathrm{~V})$ and frequency of $75 \mathrm{kHz}(\mathrm{fac}=75 \mathrm{kHz})$ at room temperature. The direct piezoelectric coefficients $\left(d_{33}\right)$ of the poled samples were tested by using a quasi-static piezo- $d_{33}$ meter (ZJ-3 A, China), and their planar electromechanical coupling factor $\left(k_{\mathrm{p}}\right)$ was measured using an impedance analyzer (HP 4299A). The $\varepsilon_{\mathrm{r}}$ and loss factor

This article is protected by copyright. All rights reserved. 
( $\tan \delta)$ were measured using an LCR analyzer (HP 4980, Agilent, USA) at room temperature. The $P-E$ hysteresis loops were measured at $10 \mathrm{~Hz}$ using a radiant precision workstation (USA) with non-poled ceramics. The unipolar strain curves of non-poled samples were measured using an MTI 2000 photonic sensor under an electric field of $30 \mathrm{kV} / \mathrm{cm}$ at room temperature.

\section{Results and discussion}

The common analysis techniques (e.g., composition-dependent XRD patterns and $\varepsilon_{\mathrm{r}}-T$ curves) have testified to the existence of an R-T phase boundary [13] [Figs. S1-3 in Supporting Information]. However, further analysis of the R-T phase boundary has not been performed, especially at low temperatures $\left(\leq 0^{\circ} \mathrm{C}\right)$. To further investigate the phase transition sequence of the R-T phase boundary, we measured the temperature-dependent powder XRD patterns of the ceramics with $x=0.03$, as shown in Fig. $1(a)$. The phase structure strongly depended on the measurement temperatures [Fig. 1(b)]. The apparent splitting of the $[002]_{\mathrm{PC}}$ and $[200]_{\mathrm{PC}}$ peaks was observed from $-150{ }^{\circ} \mathrm{C}$ to $200{ }^{\circ} \mathrm{C}$ [Fig. 1 (b)]. At $T=-150{ }^{\circ} \mathrm{C}$, the intensity of the $[002]_{\mathrm{PC}}$ peak (abbreviated as $I_{002}$ ) was slightly higher than that of $[200]_{\mathrm{PC}}$ peak (abbreviated as $I_{200}$ ), indicating the coexistence of rhombohedral $(R)$ and orthorhombic (O) phases, due to the absence of a tetragonal (T) phase at such low temperatures [14]. With increasing temperature, $I_{002}$ gradually decreased, but $I_{200}$ increased [Fig. 1 (b)]. At $T=0$ ${ }^{\circ} \mathrm{C}, I_{200}$ was slightly higher than $I_{002}$, indicating the involvement of a T phase [15]. As the

This article is protected by copyright. All rights reserved. 
temperature increased up to $200{ }^{\circ} \mathrm{C}$, the ratio of $I_{200} / I_{002}$ was found to be $2: 1$, suggesting the predominant existence of the T phase.

Subsequently, we refined the powder XRD patterns in Fig. $1(\mathrm{a})$ using $\mathrm{KNbO}_{3}$ modes and the Maud software package [16]; the refined results are shown in Figs. 2(a-c) and Table S1. The high matching and low $R_{\mathrm{w}}$ and Sig values suggest that the appropriate modes were selected. In order to identify whether the $\mathrm{O}$ phase existed or not at $T=0^{\circ} \mathrm{C}$, we employed two modes (i.e., $\mathrm{R}+\mathrm{T}$ phases and $\mathrm{R}+\mathrm{O}+\mathrm{T}$ phases) to refine the phase structure at $0{ }^{\circ} \mathrm{C}$ [Fig. $\mathrm{S} 4$ in Supporting Information]. The results suggest that the $\mathrm{R}+\mathrm{T}$ mode matched better than the $\mathrm{R}+\mathrm{O}+\mathrm{T}$ mode. Therefore, in this work, we consider the phase structure at $\mathrm{T}=0{ }^{\circ} \mathrm{C}$ to be an $\mathrm{R}-\mathrm{T}$ coexistence phase. Below, we discuss the variation of the phase transition sequence with temperature [Fig. 3] as revealed by the temperature-dependent Raman spectra.

The Raman spectrum is a powerful tool for analyzing changes in crystal structures [17]. For KNN-based ceramics, the main Raman vibrations stem from the $\mathrm{NbO}_{6}$ octahedron [18]. The $\mathrm{NbO}_{6}$ vibrations include six modes, $1 \mathrm{~A}_{1 \mathrm{~g}}\left(v_{1}\right)+1 \mathrm{E}_{\mathrm{g}}\left(v_{2}\right)+2 \mathrm{~F}_{1 \mathrm{u}}\left(v_{3}, v_{4}\right)+\mathrm{F}_{2 \mathrm{~g}}\left(v_{5}\right)+\mathrm{F}_{2 \mathrm{u}}\left(v_{6}\right)$, where $1 \mathrm{~A}_{1 \mathrm{~g}}\left(v_{1}\right)+1 \mathrm{E}_{\mathrm{g}}\left(v_{2}\right)+1 \mathrm{~F}_{1 \mathrm{u}}\left(v_{3}\right)$ are stretching modes and the rest are bending modes [18]. Furthermore, the $\mathrm{A}_{1 \mathrm{~g}}\left(v_{1}\right)$ mode represents a double-degenerate symmetric $\mathrm{O}-\mathrm{Nb}-\mathrm{O}$ stretching vibration, which is widely used to determine phase transitions [18]. Figure S5 shows the Raman spectra as a function of temperature for the ceramics with $x=0.03$. Spectra in the range of $500-700 \mathrm{~cm}^{-1}$ were fitted to show the variations in the $A_{1 g}\left(v_{1}\right)$ and This article is protected by copyright. All rights reserved. 
$E_{g}\left(v_{2}\right)$ modes with respect to peak position, FWHM, and intensity [Figs. 4(a)-(c)]. In the absence of any phase transitions, we would expect a steady phonon softening and a gradually increasing FWHM [19]. Instead, we observed four obvious anomalies, denoted as I, II, III, and IV.

Anomaly I occurred at $T=-125^{\circ} \mathrm{C}$ in the peak position and FWHM of the $\mathrm{A}_{1 \mathrm{~g}}\left(v_{1}\right)$ mode, and in both the FWHM and intensity of the $E_{g}\left(v_{2}\right)$ mode, suggesting a phase transition. As we know, the $T_{\mathrm{R}-\mathrm{O}}$ of pure $\mathrm{KNN}$ is about $-125^{\circ} \mathrm{C}$, below which a dominant $\mathrm{R}$ phase should be observed [14]. Considering the results from the temperature-dependent XRD patterns [Fig. 1(b)], an R-O phase was observed at $T \leq-50^{\circ} \mathrm{C}$. Therefore, anomaly I was caused by the phase transition from a single $\mathrm{R}$ phase to an $\mathrm{R}-\mathrm{O}$ coexistence phase. Here, the R phase was observed at $T<-125^{\circ} \mathrm{C}$ in the temperature-dependent Raman spectra [Figs. 4(a-c)], but was absent from the temperature-dependent powder XRD patterns [Fig. 1(b)], which we attributed to the successive phase transition state $[20,21]$. It was previously reported that the O-T phase boundary of KNN-based ceramics exhibited a successive transition state, accompanied by a successive variation of the synchrotron powder XRD patterns [20]. The common XRD technique cannot accurately reflect such a delicate successive transition state. Fortunately, due to its high sensitivity to variations in crystal structure, the Raman technique clearly revealed the successive transition state of the O-T phase boundary [21]. In addition, the different temperature control systems for the

This article is protected by copyright. All rights reserved. 
temperature-dependent XRD patterns and the Raman spectra measurements may also account for the difference of temperature control.

Anomaly II was characterized by an abruptly decreasing peak position and intensity of the $\mathrm{A}_{1 \mathrm{~g}}\left(v_{1}\right)$ mode at $-50{ }^{\circ} \mathrm{C}$. As shown in Fig. 3, the sharp decrease of the $\mathrm{O}$ phase occurred around at $-50{ }^{\circ} \mathrm{C}$. Therefore, we attribute this anomaly to the abrupt change in $\mathrm{O}$ phase content. Previously, applications of convergent beam electron diffraction (CBED) and Cs-corrected transmission electron microscopy (TEM) could not find evidence of an O phase in the R-T phase boundary at room temperature [6-8]. In addition, the Rietvled refinement also suggested an R-T coexistence phase instead of R-O-T coexistence phase [see Figure S4 in Supporting Information]. Hence, we assigned the area between the anomalies II and III as the R-T coexistence phase zone. Furthermore, we found that a stable R-T coexistence phase existed in the temperature range -25 to $50{ }^{\circ} \mathrm{C}$, which we observed in the temperature-dependent XRD patterns at $0{ }^{\circ} \mathrm{C} \leq T \leq 50{ }^{\circ} \mathrm{C}$ [Fig. 3]. In addition, a similar diffusion behavior was also observed in other KNN-based ceramics possessing an R-T phase boundary, which improved the thermal stability [22].

The two anomalies III and IV were observed at $50{ }^{\circ} \mathrm{C}$ and $150{ }^{\circ} \mathrm{C}$, respectively. Considering the results shown in Fig. 1(b), we attribute the area between the anomalies III and IV to the continuous decrease in R phase content. The abrupt change (anomaly IV) in the peak position and FWHM of the $E_{g}\left(v_{2}\right)$ mode at $150{ }^{\circ} \mathrm{C}$ was caused by the sharp reduction in $\mathrm{R}$ 
phase content, above which we expect a dominant T phase [2,3]. Finally, we know to expect a cubic (C) phase at $T>T_{C}[2,4,5]$. Therefore, we summarize the structural evolution of R-T phase boundary as follows: Rhombohedral $\left(R,<-125^{\circ} \mathrm{C}\right) \rightarrow$ Rhombohedral+Orthorhombic $\left(R+O,-125^{\circ} \mathrm{C}\right.$ to $\left.0{ }^{\circ} \mathrm{C}\right) \rightarrow$ Rhombohedral + Tetragonal $\left(R+T, 0{ }^{\circ} \mathrm{C}\right.$ to $\left.150{ }^{\circ} \mathrm{C}\right) \rightarrow$ dominating Tetragonal $\left(T, 200^{\circ} \mathrm{C}\right.$ to $\left.T_{\mathrm{C}}\right) \rightarrow$ Cubic $\left(C,>T_{\mathrm{C}}\right)[$ Fig. $4(\mathrm{a})]$.

\section{Ferroelectric Domains}

Considering the important role of ferroelectric domains in the piezoelectricity of KNN-based ceramics, the vertical PFM measurement was performed [Figs. 5(a1)-(c2)]. First, we scanned the surface with an AC voltage (3 V) [Figs. 5(a1) and (b1)] [23]. We found ferroelectric domains on a scale of 1-3 $\mu \mathrm{m}$, accompanied by a strong piezoresponse (e.g., amplitude of 200 pm) [Figs. 5(a1) and (b1)]. The observed piezoresponse was obviously stronger than those seen in other results [23]. Due to the involvement of the R-T phase boundary, the ferroelectric domains exhibited irregular structures, which were also observed in KNNS-BNKZ ceramics with an R-T phase boundary [22]. Then, a pattern of bias voltage was used to "write" the area [Fig. 5(a1)]. After the "writing" was finished, the amplitude and phase were immediately recorded, as shown in Figs. 5(a2)-(b2). The brightness of the amplitude was evidently enhanced by domain switching under the bias voltages [Fig. 5(a1)]. We observed an appreciable contrast in brightness accompanied by a phase difference near $180^{\circ}$ in the phase image [Fig. 5(b1)], strongly indicating a sufficient domain orientation. Here, the voltage necessary to switch the domains was about $10 \mathrm{~V}$, which is much lower 
than that required by highly textured $\left(\mathrm{Pb}_{0.8725} \mathrm{Sm}_{0.085}\right)\left(\mathrm{Ti}_{0.98} \mathrm{Mn}_{0.02}\right) \mathrm{O}_{3}$ ceramics [24].

$\mathrm{MnO}_{2}$-modified $\left(\mathrm{Na}_{0.5} \mathrm{~K}_{0.5}\right) \mathrm{NbO}_{3}-\left(\mathrm{Bi}_{0.5} \mathrm{Li}_{0.5}\right) \mathrm{TiO}_{3}-\mathrm{BaZrO}_{3}$ ceramics with an R-T phase boundary also had a similarly low driven-voltage for the complete reorientation of the domain, indicating easy domain switching [25]. After $30 \mathrm{~min}$, the amplitude and phase of the area were recorded again. This time, we observed a slightly faded brightness when comparing the amplitude images after "writing" domains 30 minutes [Fig. 5(c1)] and 0 minute [Fig. 5(b1)], and we found a reduction in the center area of the phase images when comparing Fig. 5(c2) and Fig. 5(b2), indicating that the ferroelectric domains reverted back to their initial relaxed state. We attribute the turning back of the domains to the relaxation behavior reported in our previous publication [7]. Thus, as shown by the results of vertical PFM measurement, the domains of the ceramics $(x=0.03)$ with an R-T phase boundary were apt to switch under an external electric field, which effectively benefited the piezoelectric properties.

To investigate the effects of the R-T phase boundary on the piezoelectric properties, the $d_{33}$ and $k_{\mathrm{p}}$ values were measured for the ceramics with varying $x$ and $y$, as shown in Figures 6(a) and (b). For increasing values of both $x$ and $y, d_{33}$ first increased and then decreased. We observed the optimum piezoelectric properties (e.g., $d_{33} \sim 450 \pm 5 \mathrm{pC} / \mathrm{N}$ and $k_{\mathrm{p}} \sim 0.50 \pm 0.02$ ) in the ceramics with $x=0.03$ and $y=0.035$ that possessed the R-T phase boundary. Considering the relatively high $T_{\mathrm{C}}$ of $250^{\circ} \mathrm{C}$ [Fig. S3 in Supporting Information], the overall performance of the ceramics with $x=0.03$ and $y=0.035$ presented in this work is superior to that of the

This article is protected by copyright. All rights reserved. 
highly textured LF4T ceramics (e.g., $d_{33} \sim 416 \mathrm{pC} / \mathrm{N}$ and $T_{\mathrm{C}} \sim 253^{\circ} \mathrm{C}$ ) reported by Saito et al., which is promising for the adoption of our KNN-based ceramics in practical applications [4]. Here, both the R-T phase boundary and the ferroelectric domains were responsible for the enhancement of the piezoelectric properties $[26,27]$. Due to the coexistence of multiple phases in the R-T phase boundary, polarization rotation became easy and polarization anisotropy was significantly reduced by the flattening free energy $[26,27]$, leading to an improvement in the piezoelectricity. Furthermore, as discussed above, the ceramics possessing an R-T phase boundary exhibited an easy ferroelectric domain switching, which also increased the net piezoelectricity $[26,27]$.

The $\varepsilon_{\mathrm{r}}$ and $\tan \delta$ of ceramics with varying $x$ and $y$ under different measurement frequencies (e.g., $1 \mathrm{kHz}, 10 \mathrm{kHz}$, and $100 \mathrm{kHz}$ ) are plotted in Figs. 7(a) and (b). We found that both $\varepsilon_{\mathrm{r}}$ and $\tan \delta$ were strongly dependent on the content and type of additive. When the $x$ value of the ceramics was increased, $\varepsilon_{\mathrm{r}}$ first increased and then decreased, while $\tan \delta$ showed a slight fluctuation. When the $y$ value was increased, $\varepsilon_{\mathrm{r}}$ gradually increased, while $\tan \delta$ first remained unchanged before increasing with $y$. We obtained the optimal dielectric properties (e.g., $\varepsilon_{\mathrm{r}}^{\sim} 2240$ and $\tan \delta^{\sim 0.04}$ ) in the ceramics with $x=0.03$ and $y=0.035$ due to the R-T phase boundary [28]. Generally, both the dielectric and the ferroelectric properties play a role in the piezoelectric properties of ferroelectric materials, according to the relationship $d_{33} \propto \alpha \varepsilon_{\mathrm{r}} P_{\mathrm{r}}$, where $\alpha$ is the electrostrictive coefficient, $\varepsilon_{\mathrm{r}}$ is the relative dielectric constant, and $P_{\mathrm{r}}$ is the remanent polarization $\left(P_{\mathrm{r}}\right.$ is shown in Figs. S8(c-d)) $[29,30]$. The equation

This article is protected by copyright. All rights reserved. 
indicates that $d_{33}$ and $\varepsilon_{\mathrm{r}} P_{\mathrm{r}}$ should display a similar variation. Figs. 7(c) and (d) depict the $d_{33}$ and $\varepsilon_{\mathrm{r}} P_{\mathrm{r}}$ curves of the ceramics with varying $x$ and $y$. We found a highly similar variation in the $d_{33}$ and $\varepsilon_{\mathrm{r}} P_{\mathrm{r}}$ curves, indicating that the increased $\varepsilon_{\mathrm{r}} P_{\mathrm{r}}$ was partly responsible for the enhanced piezoelectric properties $[29,30]$.

Figure 8(a) shows the unipolar strain curves of the ceramics as a function of $x$. Fig. 8(b) exhibits the variation of the maximum strain value $\left(S_{\max }\right), d_{33}{ }^{*}$, and $d_{33}$. The maximum unipolar strain value, $0.174 \%$, was obtained in the ceramics with $x=0.03$ [Fig. 8(b)], and was higher than that of $\mathrm{CaZrO}_{3}$-modified $\mathrm{KNN}$-based ceramics ( 0.105\%) under the same electric-field level [31]. Furthermore, $S_{\max }, d_{33}$, and $d_{33}{ }^{*}$ exhibited a similar behavior as $x$ increased, i.e., they first increased and then decreased [Fig. 8(b)]. All optimal coefficients (e.g., $S_{\max } \sim 0.174 \%, d_{33} \sim 450 \pm 5 \mathrm{pC} / \mathrm{N}$, and $d_{33}{ }^{*} \sim 580 \pm 5 \mathrm{pm} / \mathrm{V}$ ) were observed in the ceramics with $x=0.03$ because of the easy ferroelectric domain switching and R-T phase boundary [32]. Therefore, we conclude that the construction of an R-T phase boundary effectively improves the piezoelectric properties and strain of KNN-based ceramics.

The fatigue behaviors of the ceramics with $x=0$ and $x=0.03$ were measured as the electric-field cycles were increased to $10^{6}$ cycles, as shown in Figs. 9(a) and (b). For both compositions, no manifest changes were observed in the $P$-E loops after the $10^{6}$ electric-field cycles, indicating fatigue-free behavior. Therefore, we extracted the change in $P_{\mathrm{r}}$ and $E_{\mathrm{C}}$ from Figs. 9(a) and (b), and compared these to other lead-free material systems 
and soft PZT (PIC151) [Figs. 9(c) and (d)] [31,33,34]. Doping with BKH slightly improved the fatigue behavior and resulted in a fatigue-free property, accompanied by unchanged and normalized $P_{\mathrm{r}}$ and $E_{\mathrm{C}}$ [Figs. 9(c) and (d)]. Previously, an enhanced fatigue behavior was reported in $\mathrm{CaZrO}_{3}$-modified $\mathrm{KNN}$ ceramics [see the blue line in Figs. 9(c) and (d)] and BCTZ ceramics [see the green line in Figs. 9(c) and (d)] [31,33-35]. Compared with these ceramics, our works displayed a fatigue-free behavior, even better than the soft PZT (PIC151) [31,32]. The improvement could be attributed to the improved density [see Figs. S7-8 in Supporting Information] and easy domain switching in the region of the R-T phase boundary [Fig. 5]. An improved density effectively reduces the possibility of micro-cracks, and easy domain switching guarantees a full and fast response to external electric fields [36].

The temperature-dependent $P-E$ loops of the ceramics are plotted in relation to $x=0$ and $x=0.03$ in Figs. $10(a)$ and (b), respectively. For the ceramics with $x=0$, the remanent polarization $\left(P_{\mathrm{r}}\right)$ remained almost unchanged, while the coercive field $\left(E_{\mathrm{C}}\right)$ quickly reduced as the temperature increased. An inverse change was observed in the ceramics with $x=0.03$; that is, $P_{\mathrm{r}}$ slightly decreased, while $E_{\mathrm{C}}$ remained almost unchanged. This phenomenon can be explained by simultaneously considering the $\varepsilon_{\mathrm{r}}-T$ curves and the domain switching. As shown in Figure S2(a), the $T_{\text {O-T }}\left(\sim 132{ }^{\circ} \mathrm{C}\right)$ of the ceramics with $x=0$ was higher than $100{ }^{\circ} \mathrm{C}$, suggesting that there was no phase transition in the measured temperature range $\left(25^{\circ} \mathrm{C}\right.$ to $100^{\circ} \mathrm{C}$ ). The increasing temperature might have facilitated domain switching and domain wall motion, thereby weakening $E_{\mathrm{C}}[23]$. For the ceramics with $x=0.03$, the increasing

This article is protected by copyright. All rights reserved. 
temperature from $25^{\circ} \mathrm{C}$ to $100{ }^{\circ} \mathrm{C}$ caused a deviation from the R-T phase boundary because the $T_{\mathrm{R}-\mathrm{T}}\left(\sim 53 \pm 5{ }^{\circ} \mathrm{C}\right)$ was much lower than $100{ }^{\circ} \mathrm{C}$, thereby decreasing $P_{\mathrm{r}}$ [23]. In addition, due to the intrinsic easy domain wall motion, the increased temperature could not reduce $E_{\mathrm{C}}$ any further; thus, $E_{\mathrm{C}}$ remained unchanged. Fig. 10 (c) shows a comparison among the normalized $P_{\mathrm{r}}$ of several kinds of $\mathrm{KNN}$-based ceramics. Previously, $\mathrm{CaMO}_{3}(\mathrm{M}=\mathrm{Zr}$ or Ti) additives were used to improve the thermal stability of KNN-based ceramics [Fig. 10(c)] [23,37]. Recently, KNN:ZnO composite ceramics were found to possess a good thermal stability [Fig. 10(c)] [38]. In this work, the ceramics with $x=0$ and $x=0.03$ both displayed an improved thermal stability that was comparable to those mentioned above. Furthermore, the ceramics with $x=0.03$ possessed a higher $d_{33}(\sim 450 \pm 5 \mathrm{pC} / \mathrm{N})$ than those mentioned above [Fig. 10(d)], suggesting a promising future in practical applications.

\section{Conclusion}

In this work, we investigated the structural evolution of the R-T phase boundary in $(0.99-x) \mathrm{K}_{0.5} \mathrm{Na}_{0.5} \mathrm{Nb}_{1-y} \mathrm{Sb}_{y} \mathrm{O}_{3}-0.01 \mathrm{CaSnO}_{3}-x \mathrm{Bi}_{0.5} \mathrm{~K}_{0.5} \mathrm{HfO}_{3}$ (where $x=0 \sim 0.05$ with $y=0.035$, and $y=0 \sim 0.07$ with $x=0.03$ ) ceramics at temperatures ranging from $-150{ }^{\circ} \mathrm{C}$ to $200{ }^{\circ} \mathrm{C}$. The common analysis techniques (e.g., composition-dependent XRD patterns and $\varepsilon_{\mathrm{r}}-T$ curves) testified to the existence of the R-T phase boundary in the ceramics with $x=0.03$. Using the temperature-dependent powder XRD patterns and Raman spectra, we further determined the structural evolution to be Rhombohedral $\left(R,<-125^{\circ} \mathrm{C}\right) \rightarrow$ Rhombohedral+Orthorhombic $\left(R+O,-125^{\circ} \mathrm{C}\right.$ to $\left.0{ }^{\circ} \mathrm{C}\right) \rightarrow$ Rhombohedral + Tetragonal $\left(R+T, 0{ }^{\circ} \mathrm{C}\right.$ to $\left.150{ }^{\circ} \mathrm{C}\right) \rightarrow$ dominating 
Tetragonal $\left(T, 200^{\circ} \mathrm{C}\right.$ to $\left.T_{C}\right) \rightarrow$ Cubic $\left(C,>T_{C}\right)$. In addition, the enhanced electrical properties (e.g., $d_{33} \sim 450 \pm 5 \mathrm{pC} / \mathrm{N}, d_{33}{ }^{*} \sim 580 \pm 5 \mathrm{pm} / \mathrm{V}, k_{\mathrm{p}} \sim 0.50 \pm 0.02$, and $T_{\mathrm{C}} \sim 250{ }^{\circ} \mathrm{C}$ ), the fatigue-free behavior, and the good thermal stability were exhibited in the ceramics with $x=0.03$. Both the R-T phase boundary and easy domain switching were responsible for the enhanced electrical properties. Therefore, we believe that this work improves understanding of the physical mechanism behind the R-T phase boundary in KNN-based ceramics and is an important step towards their adoption in practical applications.

\section{Acknowledgments}

Authors gratefully acknowledge the supports of the National Science Foundation of China (NSFC Nos. 51722208, 51332003, 51272164) and by the King Abdullah University of Science and Technology (KAUST). We thank Ms. Hui Wang for measuring the FE-SEM patterns.

\section{References}

[1] Hong C, Kim H, Jo W, et al. Lead-free piezoceramics-where to move on? J. Materiom. 2016;2: 1-24.

[2] Li J, Wang K, Zhu F, et al. (K,Na) $\mathrm{NbO}_{3}$-Based Lead-Free Piezoceramics: Fundamental Aspects, Processing Technologies, and Remaining Challenges. J. Am. Ceram. Soc. 2013;96: 3677-3696.

This article is protected by copyright. All rights reserved. 
[3] Rödel, J, Webber K, Dittmer R, et al. Transferring lead-free piezoelectric ceramics into application. J. Eur. Ceram. Soc. 2015;35: 1659-1681.

[4] Saito Y, Takao H, Tani T, et al. Lead-free piezoceramics. Nature. 2004;432: 84-87.

[5] Wu J, Xiao D, Zhu J, et al. Potassium-Sodium Niobate Lead-Free Piezoelectric Materials: Past, Present, and Future of Phase Boundaries. Chem. Rev. 2015;115: 2559-2595.

[6] Xu K, Li J, Wu J, et al. Superior Piezoelectric Properties in Potassium-Sodium Niobate Lead-Free Ceramics. Adv. Mater. 2016;28: 8519-8523.

[7] Zheng T, Wu H, Wu J, et al. The structural origin of enhanced piezoelectric performance and stability in lead free ceramics. Energy. Environ. Sci. 2017;10: 528-537.

[8] Wu J, Xiao D, Zhu J, et al. Potassium-sodium niobate lead-free piezoelectric ceramics: recent advances and perspectives. J. Mater. Sci: Mater. Electron. 2015;26: 9297-9308.

[9] Shrout T, Zhang S, Lead-free piezoelectric ceramics: Alternatives for PZT? J. Electroceram. 2007;19: 113-126.

[10] Zuo R, Fu J, Lv D, et al. Antimony Tuned Rhombohedral-Orthorhombic Phase Transition and Enhanced Piezoelectric Properties in Sodium Potassium Niobate. J. Am. Ceram. Soc. 2010;93: 2783-2787.

[11] Tao H, Wu J, Zheng T, et al. New $(1-x) \mathrm{K}_{0.45} \mathrm{Na}_{0.55} \mathrm{Nb}_{0.96} \mathrm{Sb}_{0.04} \mathrm{O}_{3}-x \mathrm{Bi}_{0.5} \mathrm{Na}_{0.5} \mathrm{HfO}_{3}$ lead-free ceramics: Phase boundary and their electrical properties. J. Appl. Phys. 2015;118: 044102.

This article is protected by copyright. All rights reserved. 
[12] Zhang Y, Li L, Bai W, et al. Effect of $\mathrm{CaZrO}_{3}$ on phase structure and electrical properties of KNN-based lead-free ceramics. RSC Adv. 2015;5: 19647-19651.

[13] Wu B, Wu H, Wu J, et al. Giant Piezoelectricity and High Curie Temperature in Nanostructured Alkali Niobate Lead-Free Piezoceramics through Phase Coexistence. J. Am. Chem. Soc. 2016;138: 15459-15464.

[14] Egerton L, Dillon, D. Piezoelectric and dielectric properties of ceramics in the system potassium-sodium niobate. J. Am. Ceram. Soc. 1959;42: 438-442.

[15] Lv X, Wu J, Yang S, et al. Identification of Phase Boundaries and Electrical Properties in Ternary Potassium-Sodium Niobate-Based Ceramics. ACS Appl. Mater. Interfaces. 2016;8: 18943-18953.

[16] Xing J, Tan Z, Jiang L, et al. Phase transition and piezoelectric properties of $\mathrm{Nd}^{3+}$ doped nonstoichiometric (K,Na) $\mathrm{NbO}_{3}$-based lead free ceramics. Appl. Phys. Lett. 2017;110: 022905.

[17] Zhang M, Wang K, Zhou J, et al. Thermally stable piezoelectric properties of $(\mathrm{K}, \mathrm{Na}) \mathrm{NbO}_{3}$-based lead-free perovskite with rhombohedral-tetragonal coexisting phase.

Acta. Mater. 2017;122: 344-351.

[18] Rubio-Marcos F, Marchet P, Romero J, et al. Structural, microstructural and electrical properties evolution of $(\mathrm{K}, \mathrm{Na}, \mathrm{Li})(\mathrm{Nb}, \mathrm{Ta}, \mathrm{Sb}) \mathrm{O}_{3}$ lead-free piezoceramics through $\mathrm{NiO}$ doping. J. Eur. Ceram. Soc. 2011;31: 2309-2317.

This article is protected by copyright. All rights reserved. 
[19] Schütz D, Deluca M, Krauss W, et al. Lone-Pair-Induced Covalency as the Cause of Temperature-and Field-Induced Instabilities in Bismuth Sodium Titanate. Adv. Funct. Mater. 2012;22: 2285-2294.

[20] Yamada H, Matsuoka T, Kozuka H, et al. Crystal structure and phase transition behavior in $\left(\mathrm{K}_{1-\mathrm{x}} \mathrm{Na}_{\mathrm{x}}\right) \mathrm{NbO}_{3}$-based lead-free piezoelectric ceramic over a wide range of temperatures. $J$. Appl. Phys. 2016;120: 214102.

[21] Dai $Y$, Zhang $X$, Zhou G. Phase transitional behavior in $\mathrm{K}_{0.5} \mathrm{Na}_{0.5} \mathrm{NbO}_{3}-\mathrm{LiTaO}$ ceramics. Appl. Phys. Lett. 2007;90: 262903.

[22] Qin Y, Zhang J, Yao W, et al. Domain Configuration and Thermal Stability of $\left(\mathrm{K}_{0.48} \mathrm{Na}_{0.52}\right)\left(\mathrm{Nb}_{0.96} \mathrm{Sb}_{0.04}\right) \mathrm{O}_{3}-\mathrm{Bi}_{0.50}\left(\mathrm{Na}_{0.82} \mathrm{~K}_{0.18}\right)_{0.50} \mathrm{ZrO}_{3}$ Piezoceramics with High $d_{33}$ Coefficient. ACS Appl. Mater. Interfaces. 2016;8: 7257-7265.

[23] Wang $\mathrm{K}$, Yao F, Jo W, et al. Temperature-Insensitive $(\mathrm{K}, \mathrm{Na}) \mathrm{NbO}_{3}$-Based Lead-Free Piezoactuator Ceramics. Adv. Funct. Mater. 2013;23: 4079-4086.

[24] Yan Y, Zhou J, Maurya D, et al. Giant piezoelectric voltage coefficient in grain-oriented modified $\mathrm{PbTiO}_{3}$ material. Nature Commun. 2016;7: 13089.

[25] Zhang M, Wang K, Du Y, et al. High and temperature-insensitive piezoelectric strain in alkali niobate lead-free perovskite. J. Am. Chem. Soc. 2017;139: 3889-3895.

[26] Acosta M, Novak N, Jo W, et al. Relationship between electromechanical properties and phase diagram in the $\mathrm{Ba}\left(\mathrm{Zr}_{0.2} \mathrm{Ti}_{0.8}\right) \mathrm{O}_{3}-x\left(\mathrm{Ba}_{0.7} \mathrm{Ca}_{0.3}\right) \mathrm{TiO}_{3}$ lead-free piezoceramic. Acta. Mater. 2014;80: 48-55.

This article is protected by copyright. All rights reserved. 
[27] Tian Y, Chao X, Wei L, et al. Phase transition behavior and electrical properties of lead-free $\left(\mathrm{Ba}_{1-x} \mathrm{Ca}_{x}\right)\left(\mathrm{Zr}_{0.1} \mathrm{Ti}_{0.9}\right) \mathrm{O}_{3}$ piezoelectric ceramics. J. Appl. Phys. 2013;113: 184107.

[28] Lv X, Li Z, Wu J, et al. Enhanced piezoelectric properties in potassium-sodium niobate-based ternary ceramics. Materials \& Design 2016;109: 609-614.

[29] Jin L, Li F, Zhang S. Decoding the fingerprint of ferroelectric loops: comprehension of the material properties and structures. J. Am. Ceram. Soc. 2014;97: 1-27.

[30] Zheng T, Wu J, Xiao D, et al. Potassium-sodium niobate lead-free ceramics: modified strain as well as piezoelectricity. J. Mater. Chem. A 2015;3: 1868-1874.

[31] Yao F, Patterson E, Wang K, et al. Enhanced bipolar fatigue resistance in $\mathrm{CaZrO}_{3}$-modified (K,Na) $\mathrm{NbO}_{3}$ lead-free piezoceramics. Appl. Phys. Lett. 2014;104: 242912.

[32] Wang K, Yao F, Koruza J, et al. Electromechanical properties of $\mathrm{CaZrO}_{3}$ modified $(\mathrm{K}, \mathrm{Na}) \mathrm{NbO}_{3}$-based lead-free piezoceramics under uniaxial stress conditions. J. Am. Ceram. Soc. 2017;100: 2116-2122.

[33] Luo Z, Glaum J, Granzow T, et al. Bipolar and unipolar fatigue of ferroelectric BNT-based lead-free piezoceramics. J. Am. Ceram. Soc. 2011;94: 529-535..

[34] Patterson E, Cann D. Bipolar piezoelectric fatigue of Bi $\left(\mathrm{Zn}_{0.5} \mathrm{Ti}_{0.5}\right) \mathrm{O}_{3}-\left(\mathrm{Bi}_{0.5} \mathrm{~K}_{0.5}\right) \mathrm{TiO}_{3}-\left(\mathrm{Bi}_{0.5} \mathrm{Na}_{0.5}\right) \mathrm{TiO}_{3}$ Pb-free ceramics. Appl. Phys. Lett. 2012;101: 042905.

This article is protected by copyright. All rights reserved. 
[35] Glaum J, Granzow T, Rödel J. Evaluation of domain wall motion in bipolar fatigued lead-zirconate-titanate: A study on reversible and irreversible contributions. J. Appl. Phys. 2010;107: 104119.

[36] Lou X. Polarization fatigue in ferroelectric thin films and related materials. J. Appl. Phys. 2009;105: 024101.

[37] Zhang S, Xia R, Hao H, et al. Mitigation of thermal and fatigue behavior in $\mathrm{K}_{0.5} \mathrm{Na}_{0.5} \mathrm{NbO}_{3}$-based lead free piezoceramics. Appl. Phys. Lett. 2008;92: 152904.

[38] Pan Z, Chen J, Fan L, et al. Enhanced Piezoelectric Properties and Thermal Stability in the $\left(\mathrm{K}_{0.5} \mathrm{Na}_{0.5}\right) \mathrm{NbO}_{3}: \mathrm{ZnO}$ Lead-Free Piezoelectric Composites. J. Am. Ceram. Soc. 2015;98: 3935-3941.

\section{Figure Captions}

Figure 1: Temperature-dependent $\left(-150^{\circ} \mathrm{C}\right.$ to $\left.200^{\circ} \mathrm{C}\right)$ powder XRD patterns of the compositions with $x=0.03$ and $2 \vartheta=10-135^{\circ}(a)$, and enlarged patterns with $2 \vartheta=45-46^{\circ}(b)$. The XRD patterns were indexed according to the pseudo-cubic axes.

Figure 2: Enlarged Rietveld refinement of the samples with $x=0.03$ at (a) $T=-150{ }^{\circ} \mathrm{C}$, (b) $T=30$ ${ }^{\circ} \mathrm{C}$, and (c) $\mathrm{T}=200{ }^{\circ} \mathrm{C}$. The dark line represents the original data and the blue dots show the simulated data. The insets show the crystal structures of the rhombohedral, orthorhombic, and tetragonal phases, and the blue arrows exhibit the spontaneous polarization vector.

This article is protected by copyright. All rights reserved. 
Figure 3: Phase contents of the $R, O$, and T phases of ceramics with $x=0.03$, according to the results of the Rietveld refinement.

Figure 4: Temperature dependence of the $A_{1 g}\left(v_{1}\right)$ and $E_{g}\left(v_{2}\right)$ modes of the ceramics with $x=0.03$; (a) Raman shift, (b) FWHM, and (c) intensity.

Figure 5: Vertical piezoresponse force microscopy (VPFM) images of the ceramics with $x=0.03(5 \times 5 \mu \mathrm{m}) .(\mathrm{a} 1)$ and (a2) represent the amplitude and phase images, respectively. (b1) and (c1) represent the amplitude images after "writing the domain" 0 and 30 minutes, respectively, and (b2) and (c2) represent the corresponding phase images. The area marked by a red dash line was poled at a DC bias of $+10 \mathrm{~V}$; the area marked by a white dash line was poled at a DC bias of $-10 \mathrm{~V}$.

Figure 6: $d_{33}$ and $k_{\mathrm{p}}$ of KNNS-CS-BKH ceramics as functions of (a) $x$ and (b) $y$.

Figure 7: $\varepsilon_{\mathrm{r}}$ and $\tan \delta$ of the ceramics varying with (a) $x$ and (b) $y . d_{33}$ and $\varepsilon_{\mathrm{r}} P_{\mathrm{r}}$ curves of the ceramics as functions of (c) $x$ and (d) $y$.

Figure 8: (a) Dependence of the unipolar strain curves on the composition of the ceramics, and (b) $S_{\max }, d_{33}{ }^{*}$, and $d_{33}$ of the ceramics with varying values of $x . S_{\max }$ was the maximum unipolar strain value and $d_{33}{ }^{*}$ was calculated by the equation $S_{\max } / E_{\max }$.

Figure 9: $P-E$ loops of the ceramics with (a) $x=0$ and (b) $x=0.03$ after different electric-field cycles. Comparison of normalized (c) $P_{\mathrm{r}}$ and (d) $E_{\mathrm{C}}$ of several representative lead-free and lead-based piezoceramics. 
Figure 10: $P-E$ loops of the ceramics with (a) $x=0$ and (b) $x=0.03$ at different temperatures.

Comparison of the normalized (c) $P_{\mathrm{r}}$ and (d) $d_{33}$ of several KNN-based material systems.
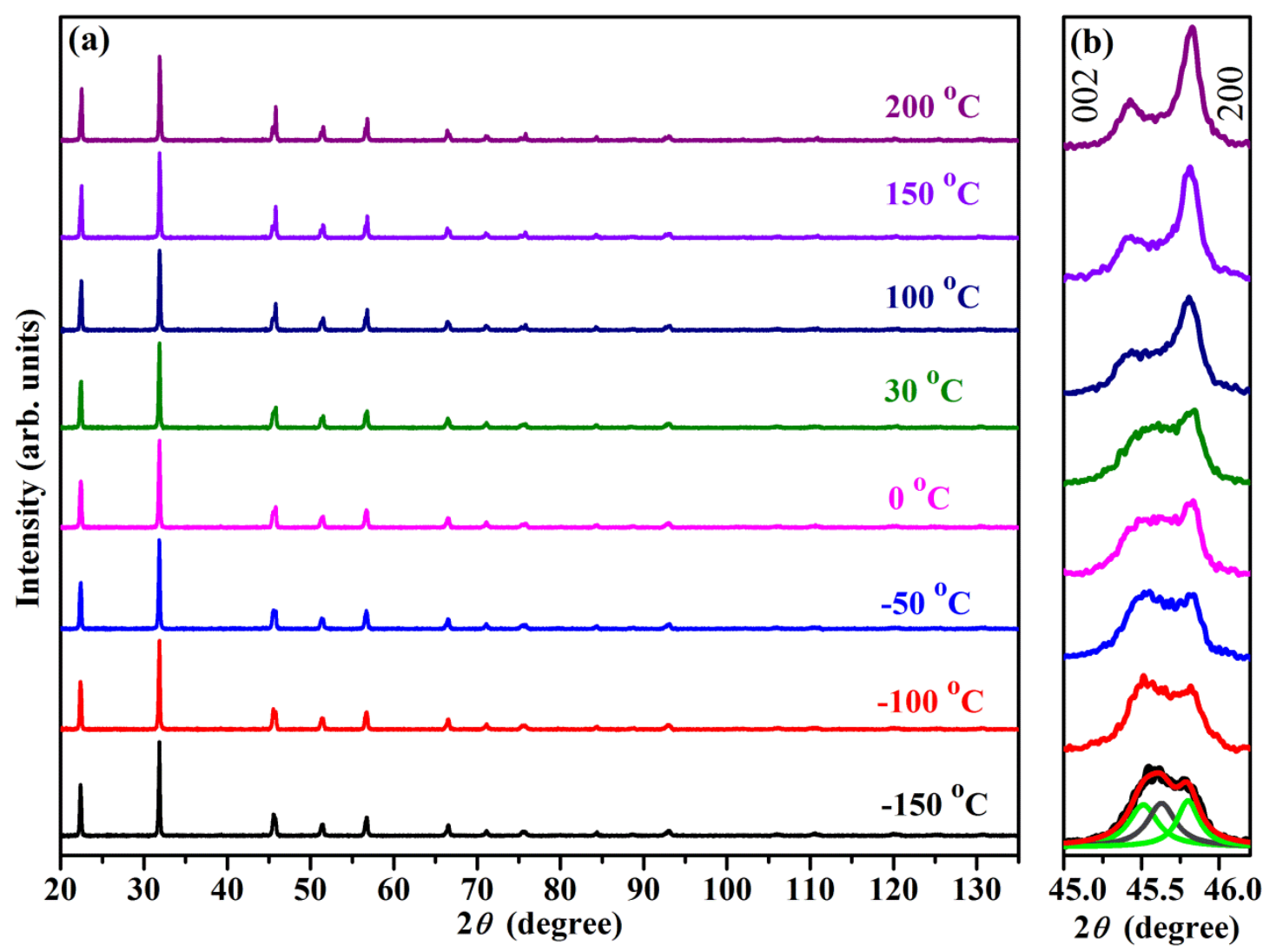

This article is protected by copyright. All rights reserved. 


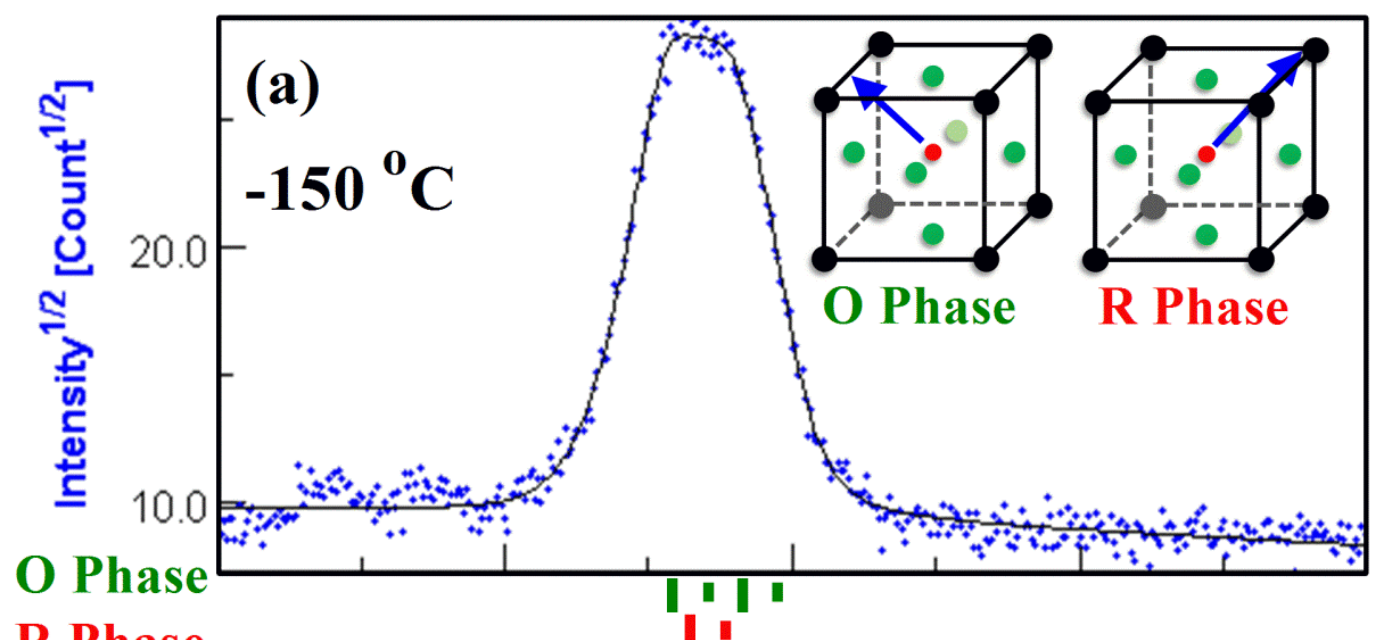

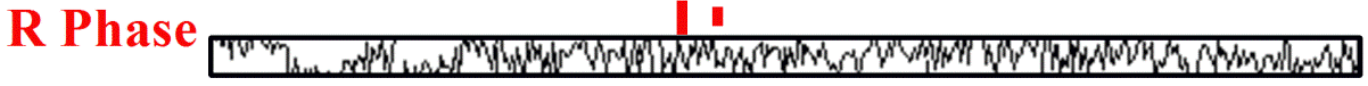

$$
\begin{array}{llll}
45.0 & 46.0 & 47.0 & 48.0
\end{array}
$$

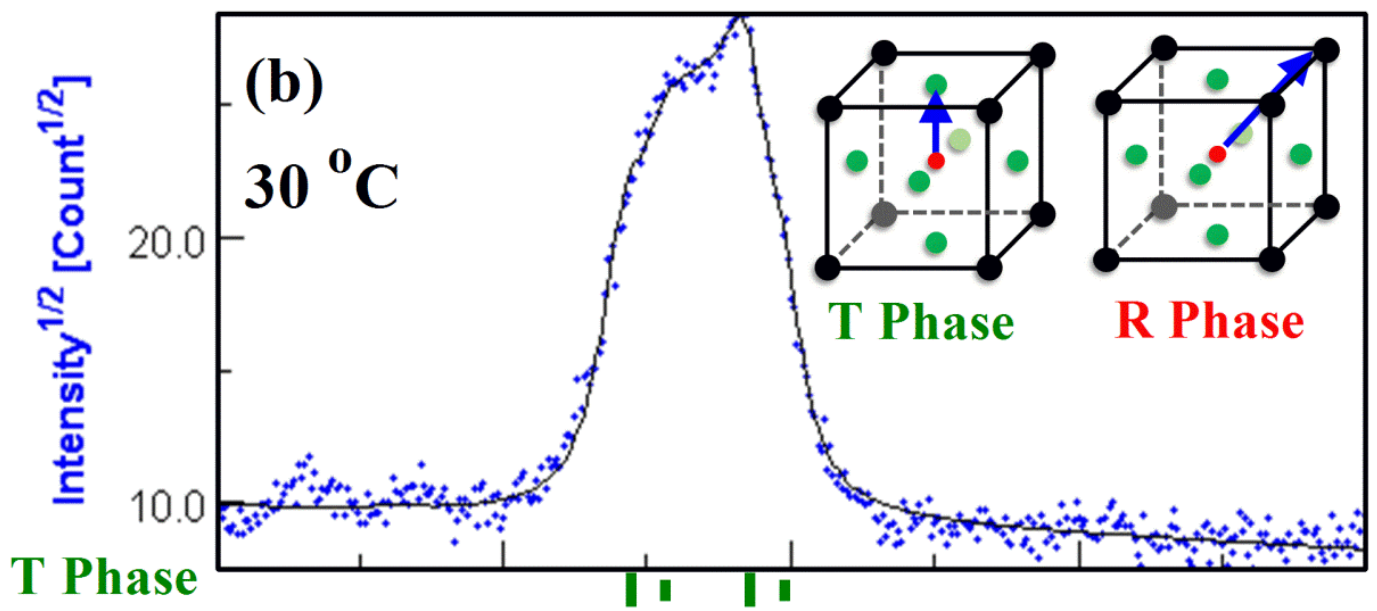

T Phase 1/11

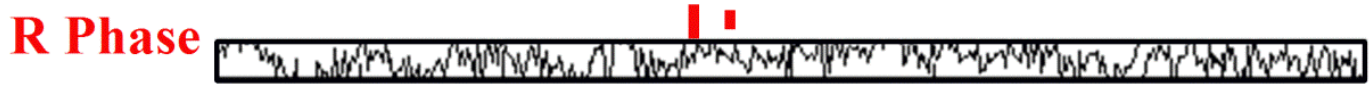
45.0 46.0 47.0 48.0

2-Theta [degrees]

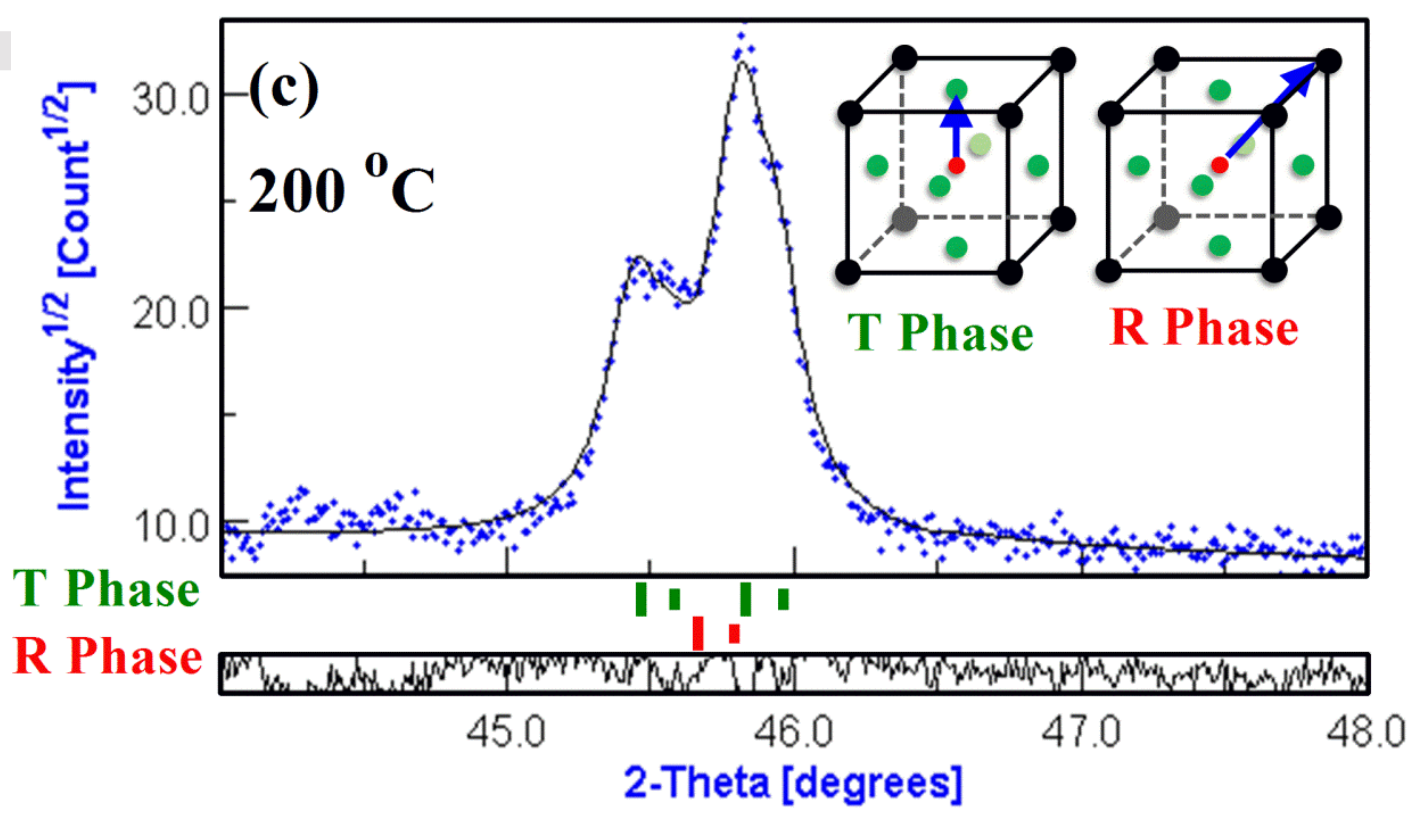

This article is protected by copyright. All rights reserved. 

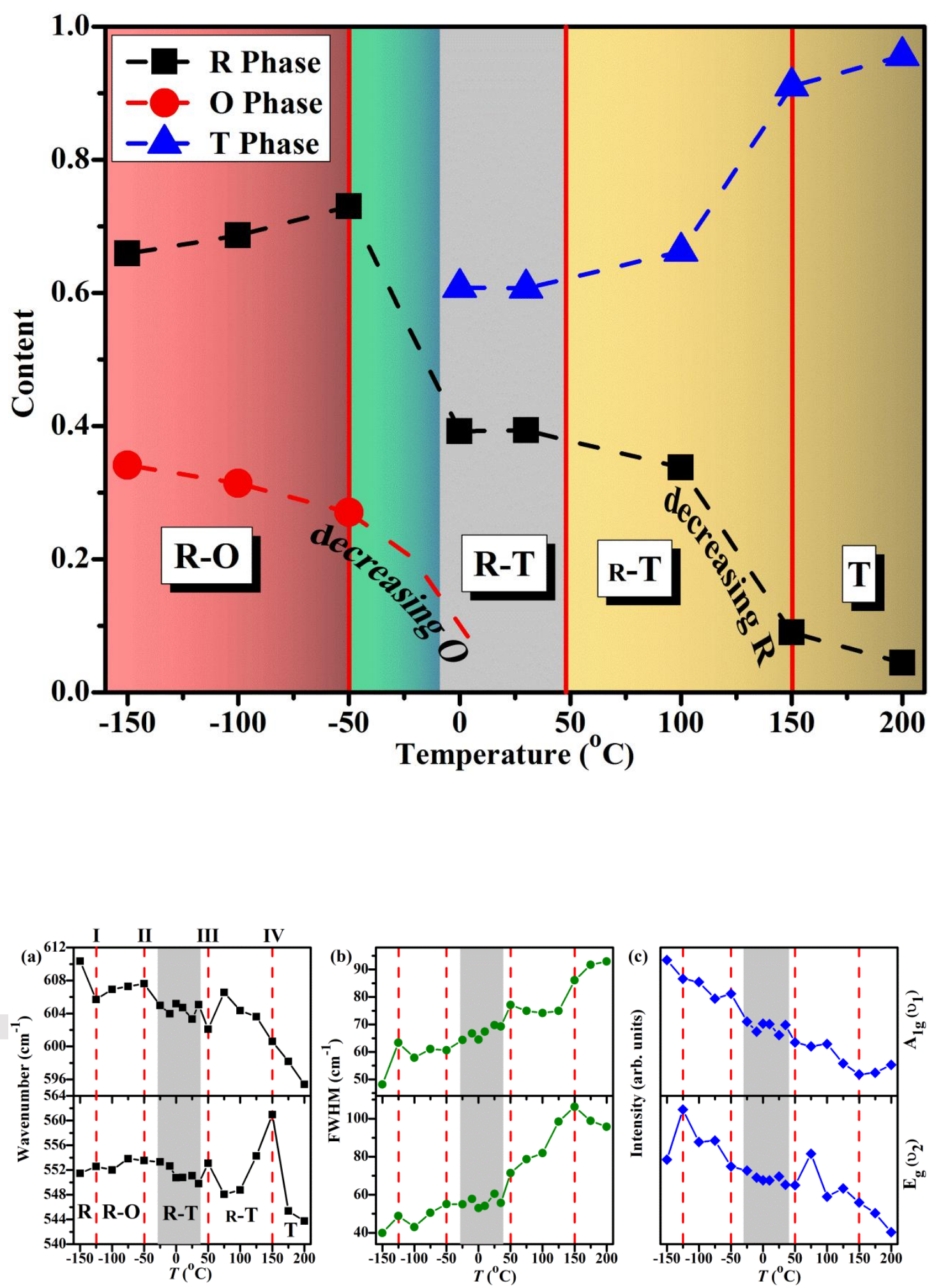

This article is protected by copyright. All rights reserved. 

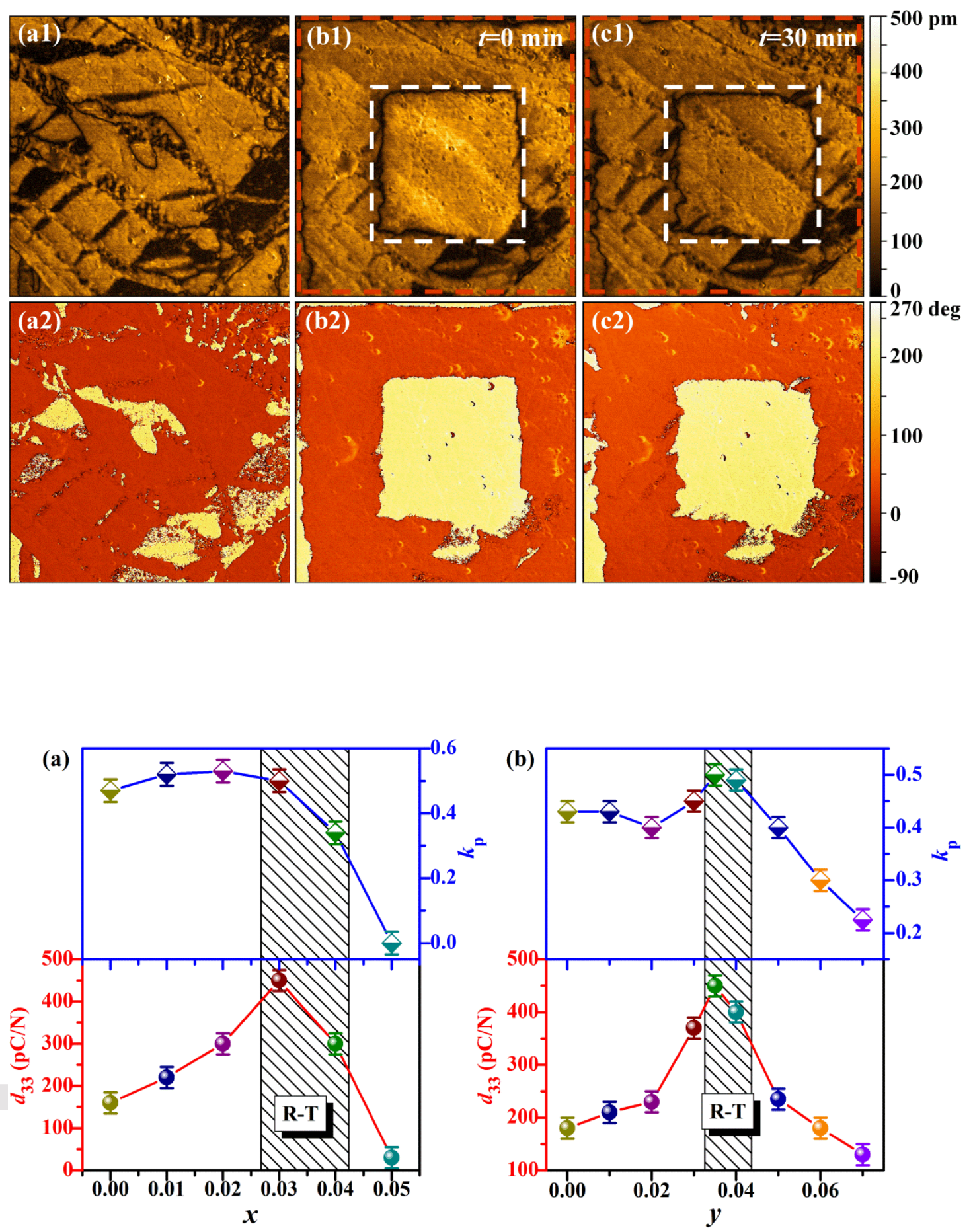

This article is protected by copyright. All rights reserved. 
(a)

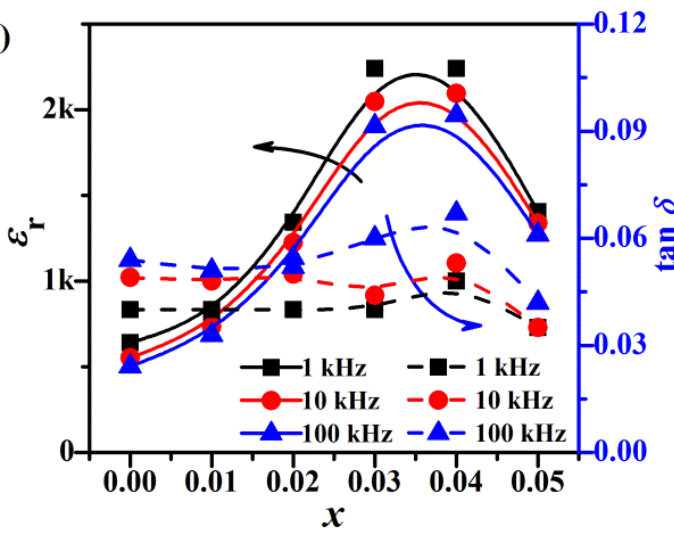

(c)

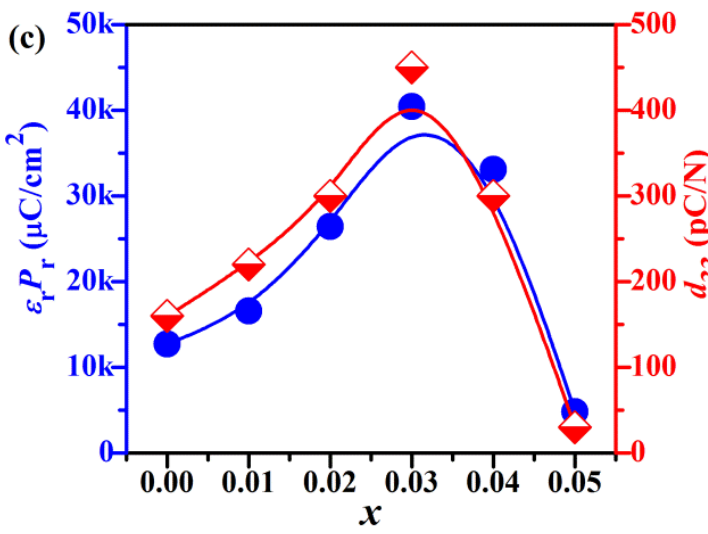

(b)

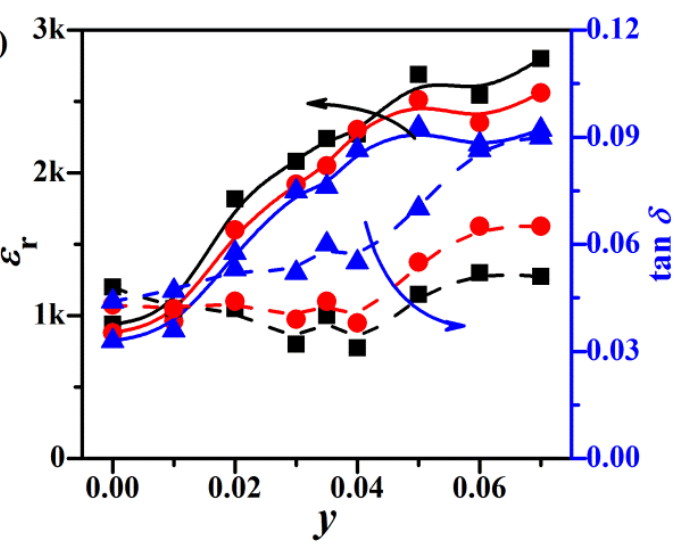

(d)

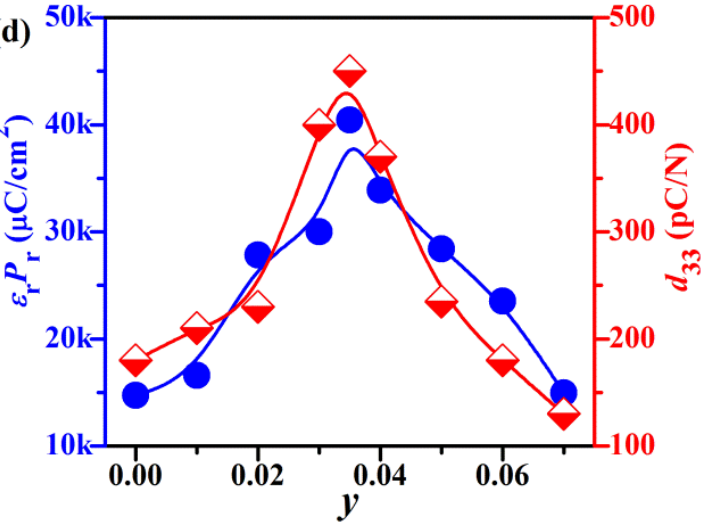

This article is protected by copyright. All rights reserved.

(a) 0.

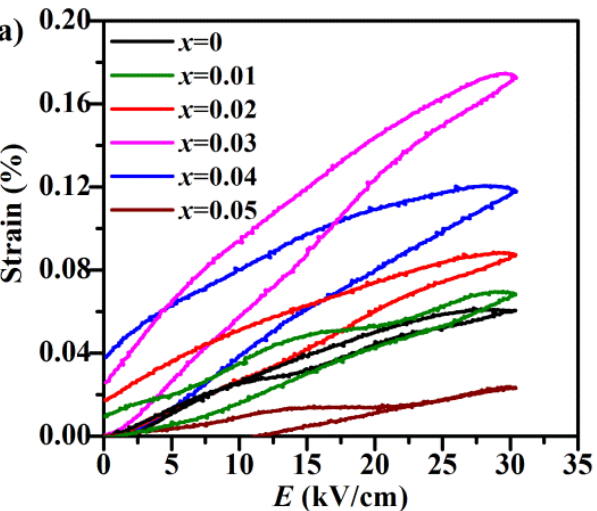

(b)

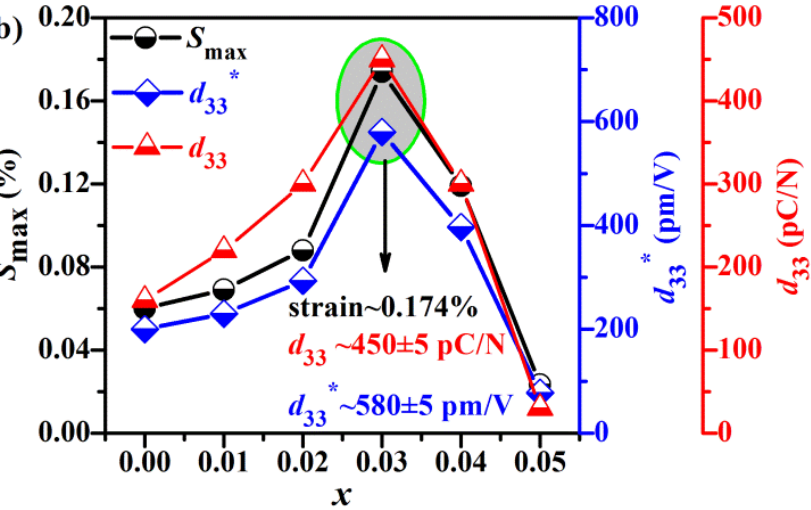



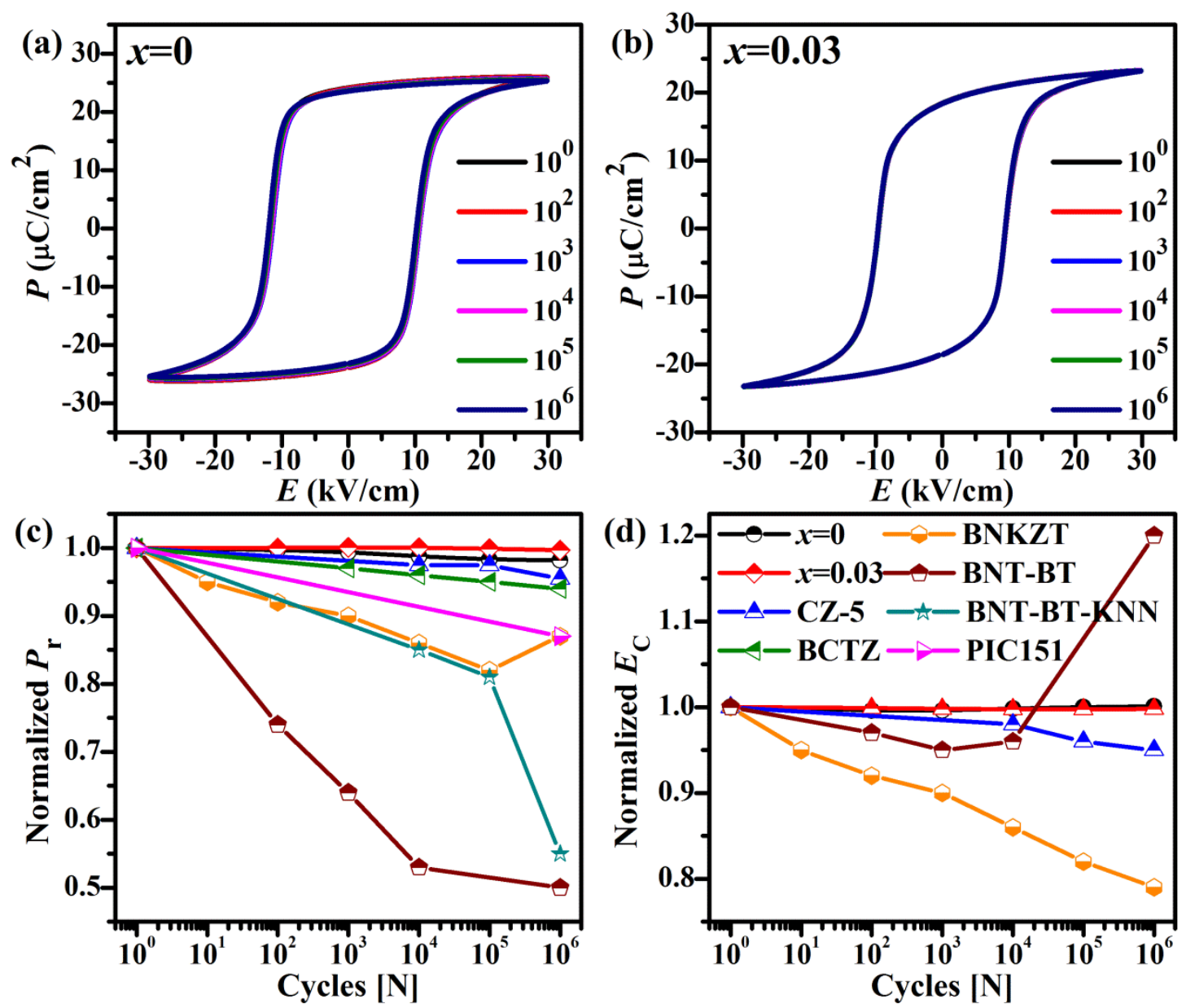

This article is protected by copyright. All rights reserved. 

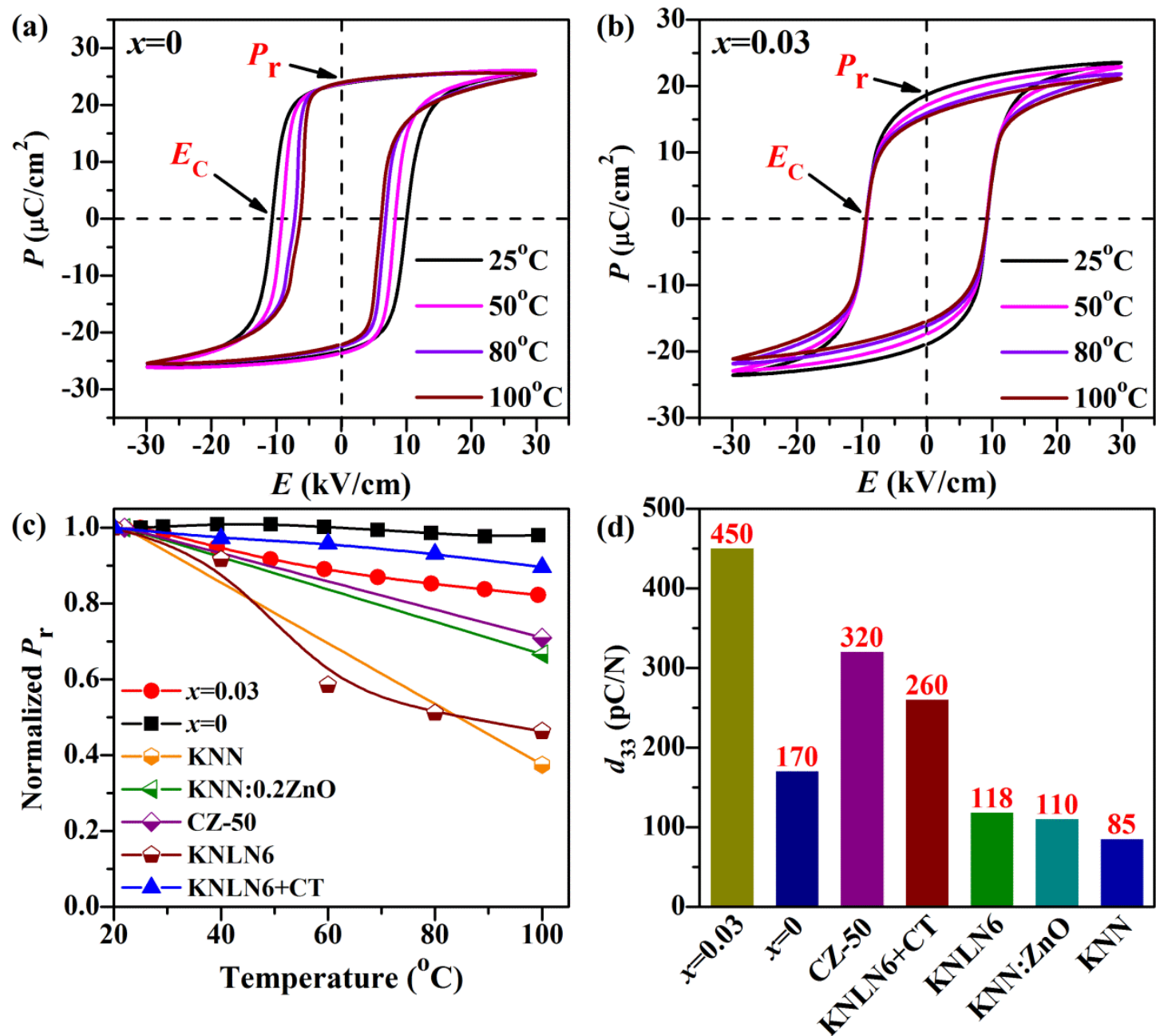

This article is protected by copyright. All rights reserved. 